\title{
Review Article \\ State of the Art and Perspectives of Inorganic Photovoltaics
}

\author{
A. Le Donne, ${ }^{1}$ A. Scaccabarozzi, ${ }^{1}$ S. Tombolato, ${ }^{1}$ S. Marchionna, ${ }^{2}$ \\ P. Garattini, ${ }^{1}$ B. Vodopivec, ${ }^{1}$ M. Acciarri, ${ }^{1}$ and S. Binetti ${ }^{1}$ \\ ${ }^{1}$ Department of Materials Science and Solar Energy Research Center (MIB-SOLAR), University of Milano-Bicocca, \\ Via Cozzi 53, 20125 Milano, Italy \\ ${ }^{2}$ Voltasolar srl, Via dell'Artigianato 8, 22078 Turate, Italy \\ Correspondence should be addressed to S. Binetti; simona.binetti@unimib.it
}

Received 23 April 2013; Accepted 22 May 2013

Academic Editors: B. Chen, F. E. Little, and A. Stoppato

Copyright (C) 2013 A. Le Donne et al. This is an open access article distributed under the Creative Commons Attribution License, which permits unrestricted use, distribution, and reproduction in any medium, provided the original work is properly cited.

\begin{abstract}
In the last decade, the fast increase of the global energy consumption, mainly related to the strong economic growth in the Far East, and the progressive depletion of the fossil fuels induced a run-up in the world oil price. Both these economic concerns and the growing global pollution pointed out that a transition toward renewable energies is mandatory. Among renewables, the conversion of sunlight into electricity by photovoltaic (PV) devices is a reliable choice to cope the growing energy consumption, due to the huge potentially extractable power (up to $120000 \mathrm{TW}$ ). The most important classes of inorganic PV devices developed in the last sixty years will be reviewed in this paper, in order to depict the state of the art of the technologies which dominate the PV market. Some novel concepts which could have an important role in the future of PV will be also described.
\end{abstract}

\section{Introduction}

Among renewable energies, the conversion of sunlight into electricity by photovoltaic (PV) devices is a reliable choice to tackle the growing global energy demand. In fact, the amount of solar energy reaching the surface of the Earth every hour can fully supply the global energy consumption over an entire year. Indeed, although a higher efficiency to cost ratio is required for the installed PV devices to make them competitive with the conventional energy resources, great strides were made in the last 30 years both in terms of installed PV power and cost reduction (see Figures 1(a) and 1(b)) [1-3].

Inorganic materials dominated the PV market from the beginning. Crystalline silicon (c-Si) solar modules are the most diffused PV devices, due to the peculiar properties and unique advantages of $\mathrm{Si}$ with respect to other $\mathrm{PV}$ absorbers (namely, availability, long lifetime, and sustainability). PV devices that compete with Si either in terms of reduced cost of production (i.e., inorganic thin films-based devices and organic solar cells) or in terms of improved efficiencies (e.g., concentrated PV systems based on III$\mathrm{V}$ compounds) are emerging. Nevertheless, the PV market share of c-Si devices was $83 \%$ in 2011 versus $17 \%$ for all thin films technologies (namely, amorphous silicon, CdTe, and
$\left.\mathrm{Cu}(\mathrm{In}, \mathrm{Ga}) \mathrm{Se}_{2}\right)$. Organic PV devices are instead in the state of advanced development and pilot production [4]. Even if their commercialization started for indoor and low-power applications, they show efficiency, stability, and lifetime not yet comparable with inorganic devices [5].

In spite of the long downward trend in retail module prices, there is a growing consensus that distributed PV systems that provide electricity in the point of use will be the first to reach widespread commercialization. Building-integrated PV (BIPV) systems [6] have in fact lower overall costs than conventional $\mathrm{PV}$, since they can provide savings both in materials and electricity costs by serving as building envelope (namely, as roofs or façades) and power generator. Furthermore, BIPV systems may be even used in stand-alone, off-grid systems, making the building self-sustaining. The strong need of efficient low-cost solar cells compatible with the requirements for BIPV (namely, deposition on different kind of substrates and long lifetime) is, therefore, expected to boost further in the next years the PV market share of thin films technologies.

In the following sections, the most important classes of inorganic PV devices will be reviewed, in order to depict both the state of the art of the technologies which dominate the PV market and some new high efficiency concept. 


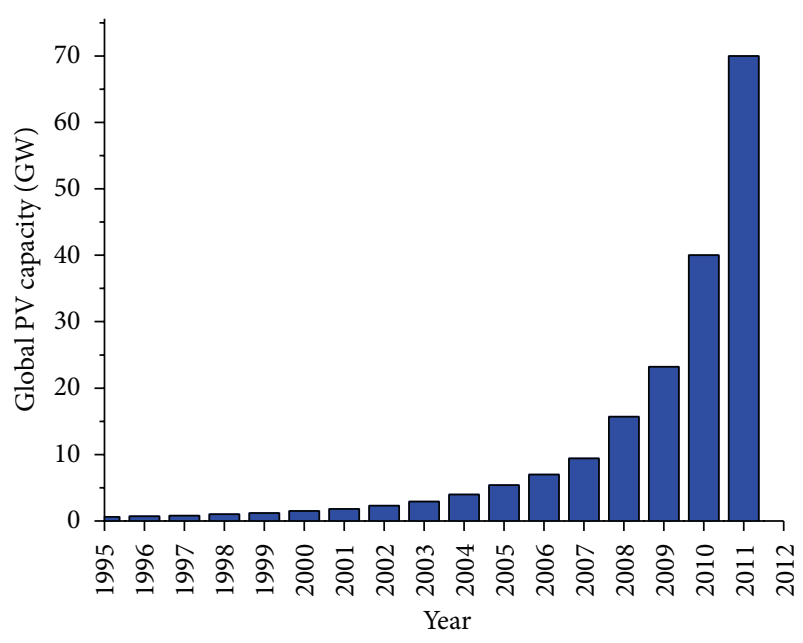

(a)



(b)

Figure 1: (a) Global PV capacity from 1995 to 2011. Data from [1]. (b) Module average selling price in 1975 and from 1995 to 2011. Data from $[2,3]$.

\section{First Generation PV Technologies: c-Si Solar Cells}

As mentioned previously, c-Si technology dominated the PV market from the beginning and is expected to retain its leading role at least for the next decade $[7,8]$. Along with its long lifetime and sustainability, the main reason for $\mathrm{c}$-Si to be the dominant PV absorber over such a long time was the huge knowledge on Si technology accumulated by the microelectronic industry. Indeed, not only has the PV community benefited from such great development but also silicon feedstock was available at reasonable prices. Due to such a strict interlink with microelectronics, p-type Czochralski $(\mathrm{Cz})$ silicon was for several decades the workhorse of the PV industry. Such high quality $\mathrm{Cz}-\mathrm{Si}$ cells benefited from more than 60 years of research activity, which resulted in the achievement of the ultimate efficiency value of 25\% [9] obtained in 2009 at the University of New South Wales (UNSW). The early performance improvements occurred in the 1950s with the development of the bulk crystal growth, followed in the 1970s by the device optimization (texturization, shallow junctions, antireflection coating, and metalizations). Finally, the improvements in bulk diffusion length, surface passivation, and the development of new device designs obtained from the 1980s on [10] resulted in the abovementioned world record by passivated emitter rear locally diffused (PERL) cells [9]. After several years of intensive R\&D, the PERL design from UNSW has been successfully commercialized by Suntech as Pluto solar cells, able to reach efficiencies higher than $19 \%$ in mass production [11]. Other PV devices with remarkable performance are commercialized by SunPower (n-type high-lifetime silicon-based cells with $22 \%$ efficiency) and by SANYO Electric Co., Ltd., Panasonic (heterojunction with intrinsic thin layer cells with 23\% lab efficiency and with $20.7 \%$ commercial efficiency) [12].
In the 1980s, due to the lower cost of multicrystalline (mc) silicon, mc-Si cells emerged as an alternative to monocrystalline ones. However, their lower quality hampered the achievement of similar efficiencies to those of $\mathrm{Cz}-\mathrm{Si}$, so that over a long time the efficiency to cost ratio has been quite similar for both technologies. More recently, a deeper understanding of the mc-Si properties led to optimized processing steps for mc-Si solar cell production devoted to the improvement of the material quality, such as $\mathrm{P}$ - and Al-gettering and $\mathrm{H}$-passivation. Thus, higher efficiencies at a still lower cost became possible, increasing the share of $\mathrm{mc}-\mathrm{Si}$ in the PV market, well ahead of Cz-Si. It is apparent from Figures 2(a) and 2(b) $[12,13]$ that nowadays one out of two modules on the market is based on mc-Si technology, this trend being ongoing and, most probably, even more pronounced in the future.

In the last decade, the strong need of PV cost reduction focused the attention on solar grade silicon (SoG-Si), whose cost has been estimated to be definitely lower than that of electronic grade Si [14]. Indeed, the capital investment for a SoG-Si feedstock production plant is expected to be significantly lower than that for a comparable production plant based on trichlorosilane technology. Consequently, the energy payback time of SoG-Si-based solar cells can be reduced to 1 year, or even less.

In spite of the significant savings in material costs associated to SoG-Si as source for Si feedstock, suitable approaches to deal with the high concentration of metal impurities typical of SoG-Si were mandatory to obtain proper device performance. Among them are the minority carrier diffusion length recovery by proper thermal annealing and the development of proper gettering processes $[15,16]$. A further key issue of the research activity on SoG-Si was the effects of compensation due to the simultaneous presence of opposite doping elements (i.e., boron and phosphorus) [17, 18]. Even if the efficiency of SoG-Si PV devices is expected to be further improved, the present record efficiency up to $16 \%$ obtained 


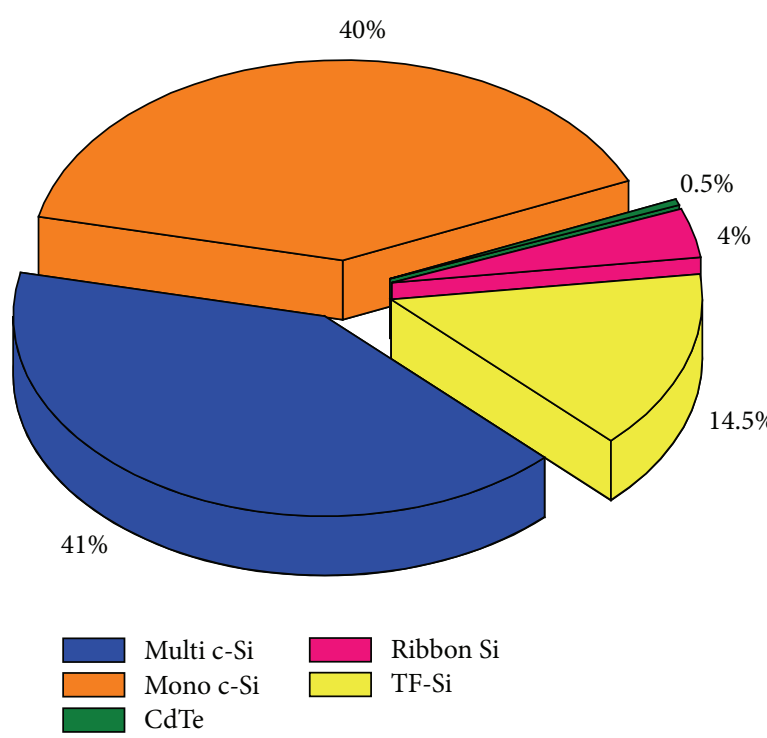

(a)

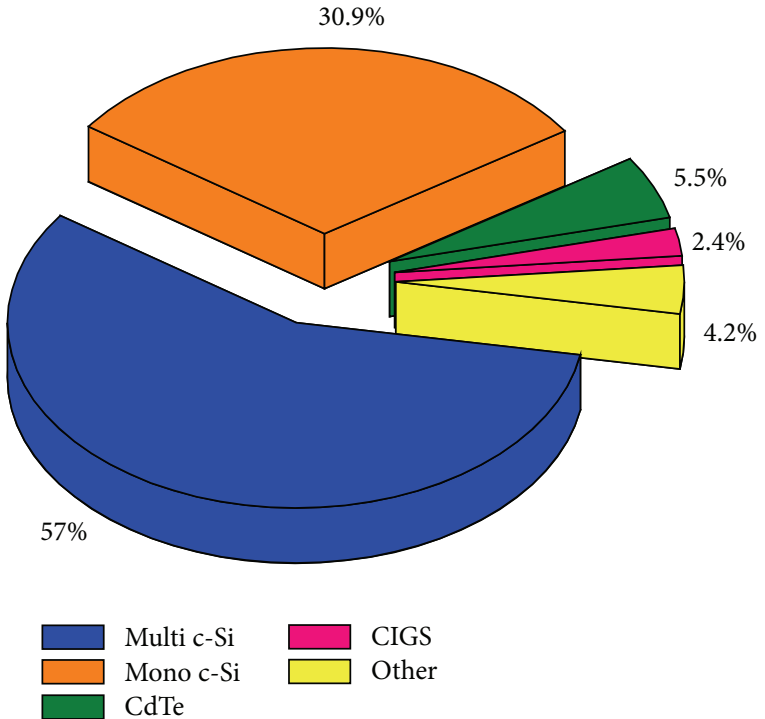

(b)

FIgure 2: (a) PV market share in 2001. Data from [12]. (b) PV market share in 2011. Data from [13].

by Silicor Materials (formerly Calisolar Inc.) is comparable to that of benchmark electronic grade Si solar cells [19].

\section{Second Generation PV Technologies: Thin Films-Based Solar Cells}

As reported in the introductive section, thin film PV technologies have been under development in the last decades as a low-cost alternative to bulk c-Si. Incidentally, this technology is the most suitable for large-scale production since the module is the final stage of an in-line process that does not require the assembly of discrete smaller cells [20].

The early research activity in this field started in the 1970s on thin film Si (TF-Si) solar cells. Many basic concepts of TF-Si solar cells were developed from then on, most of them involving TF-Si absorbers deposited via plasma-enhanced chemical vapor deposition (PECVD) [21]. Nowadays, a wide range of TF-Si solar cells have been commercialized, including single-junction amorphous silicon (a-Si), dual junction a-Si/a-Si, tandem-junction microcrystalline siliconamorphous silicon (commonly named "micromorph"), and triple-junction germanium-doped amorphous silicon (a-Si/ a-SiGe/a-SiGe). A review of commercial TF-Si PV modules (including module structure, deposition processes, and representative efficiencies for each developer) is reported in [22].

More recently, huge varieties of tellurides, selenides, and sulphides (defined as chalcogenides) have been considered due to their interesting electrical and optical properties [23]. In particular, two polycrystalline materials have been demonstrated to be proper candidates for facing the growing energy consumption: cadmium telluride (CdTe) and copper indium gallium selenides (CIGS). Unlike silicon, they all have a direct optical bandgap and high absorbtion coefficient, which allows them to be used as thin films (less than $2 \mu \mathrm{m}$ thick) absorbers. Moreover, their bandgap around $1.5 \mathrm{eV}$ (mostly depending on stoichiometry) is almost optimally matched to the solar spectrum. Relatively low growth temperatures and high tolerance to defects and impurities make them highly relevant for developments in PV. Indeed, PV modules based on CIGS and CdTe thin film technologies are already being commercialized with high quality and efficiency, as exhaustively described by Schmidtke [22].

Present-generation high-efficiency $\mathrm{CdTe}$ devices are based on p-type CdTe and n-type CdS buffer layer. CdTe absorber layers have been successfully obtained by a variety of vacuum and nonvacuum growth methods, classified as hightemperature processes (such as closed-spaced sublimation [24], or vapour transport deposition [25], with deposition temperature above $500^{\circ} \mathrm{C}$ ) or low-temperature processes (such as electrodeposition [26], spray pyrolysis [27], and sputtering [28], with deposition temperature below $450^{\circ} \mathrm{C}$ ). The as-grown $\mathrm{CdTe}$ layers usually undergo annealing to incorporate into CdTe- and CdS-specific impurities (namely, $\mathrm{CdCl}_{2}, \mathrm{O}_{2}$, or $\mathrm{Cu}$ ), which may activate or passivate native defects in the junction region [29]. Such a treatment also promotes grain growth (i.e., crystallinity) and the mixing of CdS and CdTe films; posttreated CdTe cell efficiencies can reach up to three times the initial value. The CdTe record cells have been developed by NREL laboratories [30] with the so-called superstrate configuration borosilicate glass $/ \mathrm{Cd}_{2} \mathrm{SnO}_{4} / \mathrm{Zn}_{2} \mathrm{SnO}_{4} / \mathrm{CdS} / \mathrm{CdTe} /$ metal. Last year, General Electrics Research obtained a prototype cell with power conversion efficiency of $18.3 \%$ [31], surpassing the previous CdTe record of $17.3 \%$ set in 2011 by First Solar. Finally it should be mentioned that concerns have been raised about the cadmium toxicity; however, managing $\mathrm{Cd}$ both in the manufacturing and deployment environment is possible with a proper combination of engineering and chemical hygiene practices [21]. 
The most promising thin film technology so far developed is based on copper indium gallium (di)selenide (CIGS). $\mathrm{CuIn}_{1-x} \mathrm{Ga}_{x} \mathrm{Se}_{2} / \mathrm{CdS}$ (with $x=0.25$ ) thin film solar cells can in fact exhibit an efficiency over 20\% [32]. This is the highest efficiency ever obtained for a thin film PV device, which is even similar to the best c-Si solar cells. The best CIGS solar cells are grown on soda lime glass (SLG) with the following configuration: a molybdenum $(0.5-1.0 \mu \mathrm{m})$ back contact is deposited on SLG usually by magnetron sputtering, while the CIGS absorber layer is formed mainly by the coevaporation of the elements or by the deposition of the metallic precursor layers by sputtering plus selenization. Coevaporation yielded so far devices with the highest performances [32], while the latter deposition process is preferred for large-scale production, since it allows a good uniformity over a large area. Several companies use the deposition on SLG by DC sputtering of stacked elemental layers of $\mathrm{Cu}$, In, and $\mathrm{Cu}$ $\mathrm{Ga}$ alloys with a subsequent selenization at $520-550^{\circ} \mathrm{C}$ in an atmosphere containing $\mathrm{Se}$ or $\mathrm{H}_{2} \mathrm{Se}$ [33-35]. Indeed SLG is the most common substrate, but lighter and flexible ones, like plastics or metal foils, have been recently considered to develop BIPV systems as fast as possible. However, it should be remarked that, in case a different substrate from SLG is chosen, the introduction of sodium by evaporation of $\mathrm{Na}$ containing compound $[36,37]$ is mandatory. It was demonstrated in fact that the presence of sodium boosts grain growth [38], induces grain boundaries passivation [39], and decreases the resistivity of the absorber layer [40].

Recently, finding an alternative to indium and gallium in CIGS became crucial since they are expensive rare metals that hamper a CIGS scale-up able to supply a terawatt range installed capacity. This issue may also affect $\mathrm{CdTe}$, where the showstoppers are the low abundance and high cost of tellurium. Yet there is a myriad of attractive possibilities for the synthesis of In-, Ga-, and Te-free chalcogenides which may allow terawatt range applications. Chief among them, $\mathrm{Cu}_{2} \mathrm{ZnSnS}_{4}$ (CZTS) shares similar structure with the first developed chalcopyrite matrix, that is, $\mathrm{CuInS}_{2}$ : half of the In atoms is replaced with $\mathrm{Zn}$ and another half with $\mathrm{Sn}$, resulting in the kesterite phase. The class of related materials includes other $\mathrm{I}_{2}$-II-IV-VI $\mathrm{I}_{4}$ species, such as copper zinc tin selenide (CZTSe) and the sulfur-selenium alloy CZTSSe. This class of materials consisting of p-type semiconductors, and thin film solar cells based on them normally adopt the CIGS device structure.

CZTS can be synthesized through solid state chemical reactions of $\mathrm{ZnS}, \mathrm{Cu}_{2} \mathrm{~S}$, and $\mathrm{SnS}_{2}$. However, investigations on the phase diagram of the system [41] demonstrated that the growth of CZTS without the formation of secondary phases is very challenging.

A lot of methods are known for the CZTS growth, either vacuum based, such as sputtering [42] and evaporation [43], or nonvacuum based, such as spray pyrolysis [44], sol-gel sulfurization [45], electrodeposition [46] (and other bath-based techniques), and liquid-precursor depositions [47]. Most of these techniques require additional annealing in a sulfur atmosphere at temperatures above $500^{\circ} \mathrm{C}$, but none of the mentioned pathways leads to devices with a conversion efficiency above $8.5 \%$. In 2010, IBM designed a hybrid solutionparticle approach [48], which enabled fabrication of the most efficient ( $\eta \geq 9.6 \%$ ) kesterite PV devices. The precursor slurry employed for the deposition comprises a $\mathrm{Cu}$-Sn chalcogenide solution in hydrazine with the in situ formation of readily dispersible particle-based $\mathrm{Zn}$ chalcogenide precursors, $\mathrm{ZnSe}\left(\mathrm{N}_{2} \mathrm{H}_{4}\right)$ or $\mathrm{ZnS}\left(\mathrm{N}_{2} \mathrm{H}_{4}\right)$. Once deposited on a substrate, the solution is dried at $540^{\circ} \mathrm{C}$ on a hot plate. This approach seemed so promising for the commercialization of kesterite solar cells that Solar Frontier and DelSolar Co., Ltd have partnered with IBM in developing this technology since its very beginning. Last year, IBM announced the achievement of a world-record CZTSSe solar cell with 11.1\% efficiency [49].

\section{Third Generation PV Technologies: High- Efficiency Solar Cells and New Concepts}

The key parameter to understand whether photovoltaics is economically convenient or not is the efficiency of solar energy conversion. Efficiency is a commonly used figure of merit that describes how much of the energy contained in sunlight can be converted to usable electrical power. The more efficient a solar cell, the less expensive the power produced considering fixed solar cell production (or input) costs. There are two main ways to reduce photovoltaic energy costs: the first one is reducing the cells and modules production costs and the second one is increasing the device efficiency.

Solar cells are usually made of a single $\mathrm{p}-\mathrm{n}$ junction of a semiconducting material, like silicon or gallium arsenide for instance [50]. A thorough and rigorous treatment was developed by Shockley and Queisser [51] using thermodynamical arguments to calculate the ultimate efficiency of a single junction solar cell: it is limited to $31 \%$ for unconcentrated sunlight and $40 \%$ for maximum concentration (i.e., 46000 suns) [21]. The two main physical considerations that limit conversion efficiency will be now sketched out.

Each semiconductor has unique light absorption properties that depend primarily on its energy gap, that acts like a threshold for the absorption process: photons whose energy is above the bandgap can be absorbed, while all the others cannot. Basically, the more photons are absorbed, the more electron-hole pairs are created in the semiconductor and the more current can be generated by the solar cell. This is the first important loss mechanism in photovoltaic devices: the solar spectrum is not well exploited because a significant part of it cannot be absorbed. If we consider high-energy photons only, after absorption the electron-hole pairs have much more energy than the bandgap, but they lose it with collisions with phonons or other free charge carriers in the material. This process, known as thermalization, is very fast compared to charge collection by the $\mathrm{p}-\mathrm{n}$ junction and leaves all the electrons and holes at an energy very close to the band edges. The lower the bandgap, the more amount of energy lost with thermalization. This is the second important loss mechanism in photovoltaic devices: high-energy photons are absorbed, but the energy in excess of the bandgap is lost as heat. These two loss mechanisms are present in any photovoltaic device and represent the most important 
physical limits to the efficiency of energy conversion from sunlight to electrical power [52]. In real devices other issues like contact shadowing, parasitic resistances, or nonradiative recombination also contribute to reduce the efficiency.

Different ideas have been proposed to overcome these limits, all of them aimed to a better exploitation of sunlight. After the realization of the first heterostructure devices, it was realized that stacking different semiconductors together could increase the absorption spectrum of a photovoltaic device, giving better match to the solar spectrum: this led to the development of the so-called multiple junction or tandem solar cells [53]. The concept is very simple: a tandem device consists of a series of single junction cells with different bandgaps stacked together. In this way each subcell absorbs a narrow band of the solar spectrum, and its bandgap can be tuned to minimize thermalization losses in that band. The increased number of junctions extends the overall spectral sensitivity of the device, reducing absorption losses. Multiple junction cells are connected in series in order to get the sum of the voltages generated by each junction. The current is low compared to traditional c-Si solar cells due to the reduced absorption band, and it is determined by the lowest one in the stack. It is very important to match the currents generated by each subcell to get the best performance from the tandem, and this can be done with careful design of the thicknesses of each layer. Among the emerging tandem device concepts is the all-silicon approach based on the quantum confinement effect in Si nanostructures proposed by UNSW [54]. Due to the strong confinement effect occurring when $\mathrm{Si}$ is constrained in all three dimensions, such as in quantum dots (QDs), tandem cell elements with different bandgap can be obtained by adjusting the size of Si QDs [55]. In spite of the successful realization of (n-type) Si QD/(p-type) c-Si PV devices [12], the full development of all-silicon tandem devices requires further R\&D activity [12].

The tandem design is currently used in commercial aSi solar cells [56] and in advanced concentrator or space solar cells [57]. The use of a light concentration system made of mirrors of Fresnel lenses can increase the current output of several hundred times, at a voltage that is much higher than traditional solar cells, making tandems suitable for power production plants, with also few concerns about the installation of heavy sunlight tracking systems and about the initial capital investment. The higher costs imposed by materials and fabrication are compensated by the high efficiency obtained with concentration technology, since there is no need for large area devices. Moreover, if solar power plants can be realized, there is no need to change the energy distribution system from the current plant-based to a smart grid of land-spread diffused producers. To date, the record $\mathrm{PV}$ device is a tandem cell, which scores $44.0 \%$ at 942 suns [31]. The need for high efficiency devices is self-evident in the field of space photovoltaics, for power generation on satellites: the devices of choice are multijunction tandem cells, whose costs are not actually a big concern if compared to the overall building and deployment costs of a satellite. The design is slightly different from what is used for terrestrial concentration devices, since the reference spectrum is AM0 (extraterrestrial solar spectrum [58]), while for concentration it is AM1.5D (standard terrestrial direct solar spectrum [59]), so the current matching of the tandem must be adjusted to the higher injection level and spectral differences to achieve optimal conversion efficiency. Space devices must also be reliable and radiation resistant in order to preserve their efficiency, due to the prohibitive orbital maintenance costs, and III-V technology is well suited to that [60].

The stacking of the junctions into a tandem can be done mechanically after growth or directly by switching between different materials during the same epitaxial process. The biggest constraint in a monolithically grown device is the limited tolerance for defects induced by eventual mismatch of lattice parameters and thermal expansion coefficients among the materials used in the tandem, In the case of the most widespread $\mathrm{Ge} /(\mathrm{In}) \mathrm{GaAs} / \mathrm{InGaP}_{2}$ tandem, these parameters are determined by the use of a Ge substrate. The introduction of N-based alloys has added another degree of freedom in the engineering of lattice parameters and energy gaps [61] to design and fabricate more and more efficient devices. Strain engineering and improved fabrication technology also allows the production of lattice-mismatched metamorphic devices [62]. A very important technological breakthrough would be represented by the use of $\mathrm{Si}$ as a light and robust substrate, especially for space multijunction cells. So far, the high mismatch between $\mathrm{Si}$ - and GaAs-related alloys parameters has made the realization of high efficiency devices grown directly on $\mathrm{Si}$, impossible but promising techniques of substrate patterning [63] can pave the way to III-V technology on Si.

If one can think to the tandem cells as a way to adapt the device characteristics to the solar spectrum, it is also possible to imagine that the solar spectrum itself can be adapted to a particular device. This approach is sometimes referred to as light harvesting [12]: the solar spectrum is modified and tuned to make it more blue or red rich, in order to be better absorbed by a solar cell optimized to work in that specific spectral range. This approach has the advantage of avoiding any modification in the solar cell design, needing only a spectrum-changing layer that can be put on the front or on the back of the cell. Down converting layers on the other side split high-energy "blue" photons into a pair of low-energy photons: such kind of layers can be put on the front side of a low-bandgap solar cell, in order to compensate for thermalization losses. Upconverting layers are made of materials capable of absorbing two low-energy "red" photons and emitting one with higher energy. One can think of putting this kind of layers on the rear side of a high-bandgap solar cell in order to compensate for red photons lack of absorption. Slightly different approach is down-shifting, that is basically luminescence of "red" photons excited by the UV or blue components of sunlight, that are usually poorly absorbed by solar cells; the photon balance is one to one while in downconversion it is expected to be one to two. Materials capable of up- or downconversion and downshifting of sunlight are usually made of rare earth ions dispersed in a polymer [12], so they can easily be incorporated in the commonly used encapsulants for solar modules. Drawbacks of these approaches are the quenching effect [64] that occurs when the concentration of the active ions is high enough for other recombination mechanisms to occur and become dominant 
and the typically narrow absorption bands associated with the ions' electronic transitions. These materials can be effective for efficiency increase in a widespread market given that they are cheap and abundant.

In addition to cell or spectrum tuning as discussed previously, new concepts have been proposed to increase the conversion efficiency of photovoltaic devices, based on the introduction of new physical mechanisms for charge generation or collection inside the $\mathrm{p}-\mathrm{n}$ junction.

All of the considerations that have been made previously to understand the most important physical limitations to conversion efficiency lie on the assumption that each absorbed photon can generate one single electron-hole pair; but if a photon has energy at least twice as high as the bandgap, there is no violation of the principles of conservation of energy and momentum if two electron-hole pairs are generated. This phenomenon is named multiple exciton (the electronhole quasiparticle) generation. Such generation process can lead photovoltaic devices to a better exploitation of the high energy end of the spectrum, reducing thermalization losses and increasing the efficiency. Multiple exciton generation commonly occurs in semiconductors via impact ionization of energetic electrons [65], with a higher threshold than twice the bandgap due to conservation of momentum. The Auger recombination process can also lead to an effective multiple exciton generation if relaxation of high energy excited states leads to a low energy exciton and allows the generation of another exciton. This process has been demonstrated [66] in quantum dot structures, leading to quantum efficiencies of more than $100 \%$.

A different way to better exploit the high energy photons is to collect the charge carriers before they thermalize. This approach relies on the possibility of slowing down the cooling rate of hot carriers via a phonon bottleneck effect, that has been observed in nanostructures [67]. In this way if a selective high energy contact is present, the charge can be extracted before phonon scattering processes have dissipated the energy above the bandgap. Quantum nanostructures are studied for applications in this field, because their potential to work as selective tunnel energy contacts has been demonstrated [68].

Another interesting idea is the insertion of a half-filled energy band inside the energy gap of a semiconductor, in order to allow also subgap photons to be absorbed in a double step process. It has been demonstrated [69] that if this intermediate band (IB) is characterized by a different quasi-Fermi level than conduction and valence band ones, the output voltage of the device is not changed by the presence if the intermediate band but the current is increased by the extension of the absorption coefficient to subgap spectral range. Superlattices of quantum dots can provide an effective formation of an intermediate band, and the first devices operating with the double photon absorption process have been demonstrated [70, 71]. However, so far the splitting between the Fermi levels is not achieved at room temperature, and thermal coupling between the bands degrades the performance of the devices. One possibility to enhance the IB mechanism is to couple the devices with plasmonic antennas that can increase light absorption by several hundred times. In this way a larger splitting of Fermi level is expected.

Plasmonics is an emerging field in optical science, based on the resonance of light and charge oscillation modes on the surface of metallic micro- or nanoparticles. With different designs it allows to trap light, to enhance the electric field, or to guide it inside a semiconductor absorbing film, like a solar cell [72]. In this way just very thin layers of expensive but efficient semiconductors like GaAs can be used to produce cost-effective solar cells. A thin film GaAs single junction solar cell designed with plasmonic light coupling currently scores [31] as the most efficient single junction device under unconcentrated sunlight, very close to the theoretical limit of Shockley and Queisser.

All of the novel devices efficiency boosted by the presence of nanostructures have to deal with the problem of the additional costs needed by the fabrication of the nanostructures themselves. Of course self-assembly of quantum dots should be preferred to nanolithography in terms of time and steps of fabrication, and the same is for plasmonic antennas. A good compromise may be found with concentration technologies, but only if the efficiency gain significantly compensates the higher cost. We believe that research in this field is worthwhile, since the theoretical maximum efficiencies are $68 \%$ for intermediate band, up to $86 \%$ for multiple exciton generation or hot carrier devices under maximally concentrated sunlight, as well as for tandem cells with a hypothetical infinite number of junctions [73]. These numbers are definitely much higher than the $40 \%$ ShockleyQueisser limit for single junction traditional solar cells.

\section{References}

[1] REN21, "Renewables-global status report," Tech. Rep. 48, REN21, Paris, France, 2012.

[2] P. Mints, "The history and future of incentives and the photovoltaic industry and how demand is driven," in Proceedings of the 26th European Photovoltaic Solar Energy Conference, pp. 4420-4424, Hamburg, Germany, 2011.

[3] http://www.solarbuzz.com/facts-and-figures/retail-price-environment/module-prices.

[4] Y. Su, S. Lan, and K. Wei, "Organic photovoltaics," Materials Today, vol. 15, no. 12, pp. 554-562, 2012.

[5] N. Yeh and P. Yeh, "Organic solar cells: their developments and potentials," Renewable and Sustainable Energy Reviews, vol. 21, pp. 421-431, 2013.

[6] M. Oliver and T. Jackson, "Energy and economic evaluation of building-integrated photovoltaics," Energy, vol. 26, no. 4, pp. 431-439, 2001.

[7] S. A. Mann, M. J. de Wild-Scholten, V. M. Fthenakis, W. G. J. H. M. van Sark, and W. C. Sinke, "The energy payback time of advanced crystalline silicon PV modules in 2020: a prospective study," Progress in Photovoltaics, 2013.

[8] S. W. Glunz, R. Preu, and D. Biro, "Crystalline silicon solar cells: state-of-the-art and future developments," in Comprehensive Renewable Energy, Volume 1: Photovoltaic Solar Energy, p. 353, Elsevier, New York, NY, USA, 2012.

[9] M. A. Green, “The path to $25 \%$ silicon solar cell efficiency: History of silicon cell evolution," Progress in Photovoltaics, vol. 17, no. 3, pp. 183-189, 2009. 
[10] M. A. Green, J. Zhao, A. Wang, and S. R. Wenham, "Progress and outlook for high-efficiency crystalline silicon solar cells," Solar Energy Materials and Solar Cells, vol. 65, no. 1, pp. 9-16, 2001.

[11] http://am.suntech-power.com/technology/pluto.html?lang=.

[12] "Silicon-based photovoltaics," in Handbook of Silicon Photonics, L. Vivien and L. Pavesi, Eds., Taylor \& Francis, Boca Raton, Fla, USA, 2013.

[13] E. Gazis, C. Candeliseb, M. Winskela, and R. Gross, "The status and prospects of thin-film PV as emerging technology systems," in Proceedings of the 27th European Photovoltaic Solar Energy Conference and Exhibition, pp. 4617-4622, Frankfurt, Germany, 2012.

[14] D. Kohler, B. Raabe, and S. Seren, OfUMG-Si: A New Hope, Photovoltaics International, Aachen, Germany, 12th edition, 2011.

[15] T. Buonassisi, A. A. Istratov, M. A. Marcus et al., "Engineering metal-impurity nanodefects for low-cost solar cells," Nature Materials, vol. 4, no. 9, pp. 676-679, 2005.

[16] M. D. Pickett and T. Buonassisi, "Iron point defect reduction in multicrystalline silicon solar cells," Applied Physics Letters, vol. 92, no. 12, Article ID 122103, 2008.

[17] S. Dubois, N. Enjalbert, and J. P. Garandet, "Effects of the compensation level on the carrier lifetime of crystalline silicon," Applied Physics Letters, vol. 93, no. 3, Article ID 032114, 2008.

[18] J. Libal, S. Novaglia, M. Acciarri et al., "Effect of compensation and of metallic impurities on the electrical properties of $\mathrm{Cz}-$ grown solar grade silicon," Journal of Applied Physics, vol. 104, no. 10, Article ID 104507, 2008.

[19] http://www.silicormaterials.com/application/high-efficiencypv-products.html.

[20] F. Dross, K. Baert, T. Bearda et al., "Crystalline thin-foil silicon solar cells: where crystalline quality meets thin-film processing," Progress in Photovoltaics, vol. 20, pp. 770-784, 2012.

[21] A. Luque and S. Hegedus, Eds., Handbook of Photovoltaic Science and Engineering, John Wiley \& Sons, New York, NY, USA, 2003.

[22] J. Schmidtke, "Commercial status of thin-film photovoltaic devices and materials," Optics Express, vol. 18, supplement 3, pp. A477-A486, 2010.

[23] S. Chen, X. G. Gong, A. Walsh, and S. Wei, "Electronic structure and stability of quaternary chalcogenide semiconductors derived from cation cross-substitution of II-VI and I-III-VI2 compounds," Physical Review B, vol. 79, no. 16, Article ID 165211, 2009.

[24] C. S. Ferekides, D. Marinskiy, V. Viswanathan et al., "High efficiency CSS CdTe solar cells," Thin Solid Films, vol. 361-362, pp. 520-526, 2000.

[25] W. Palosz and H. Wiedemeier, "Physical vapor transport of cadmium telluride in closed ampoules," Journal of Crystal Growth, vol. 129, no. 3-4, pp. 653-665, 1993.

[26] M. P. R. Panicker, M. Knaster, and F. A. Kroger, "Cathodic deposition of CdTe from aqueous electrolytes," Journal of the Electrochemical Society, vol. 125, no. 4, pp. 566-572, 1978.

[27] J. A. Aranovich, D. Golmayo, A. L. Fahrenbruch, and R. H. Bube, "Photovoltaic properties of $\mathrm{ZnO} / \mathrm{CdTe}$ heterojunctions prepared by spray pyrolysis," Journal of Applied Physics, vol. 51, no. 8, pp. 4260-4268, 1980.

[28] A. Gupta and A. D. Compaan, "All-sputtered 14\% CdS/CdTe thin-film solar cell with $\mathrm{ZnO}$ :Al transparent conducting oxide," Applied Physics Letters, vol. 85, no. 4, pp. 684-686, 2004.
[29] S. Smith, R. Dhere, T. Gessert, P. Stradins, T. Wang, and A. Mascarenhas, "Spatially resolved studies of grain-boundary effects in polycrystalline solar cells using micro-photoluminescence and near-field microscopy," in Proceedings of the DOE Solar Energy Technologies Conference, Denver, Colo, USA, 2004.

[30] X. Wu, "High-efficiency polycrystalline CdTe thin-film solar cells," Solar Energy, vol. 77, no. 6, pp. 803-814, 2004.

[31] M. A. Green, K. Emery, Y. Hishikawa, W. Warta, and E. D. Dunlop, "Solar cell efficiency tables (version 41)," Progress in Photovoltaics, vol. 21, no. 1, pp. 11-20, 2013.

[32] P. Jackson, D. Hariskos, E. Lotter et al., "New world record efficiency for $\mathrm{Cu}(\mathrm{In}, \mathrm{Ga}) \mathrm{Se}_{2}$ thin-film solar cells beyond $20 \%$," Progress in Photovoltaics, vol. 19, no. 7, pp. 894-897, 2011.

[33] I. M. Kötschau, A. Kampmann, T. Hahn, J. Hinze, E. Richter, and D. Schmid, "A new reactive annealing approach for large scale $\mathrm{Cu}(\mathrm{In}, \mathrm{Ga}) \mathrm{Se}_{2}$ mass production," in Proceedings of the 24 th European Photovoltaic Solar Energy Conference, pp. 2450-2454, Hamburg, Germany, 2009.

[34] S. Niki, M. Contreras, I. Repins et al., "CIGS absorbers and processes," Progress in Photovoltaics, vol. 18, no. 6, pp. 453-466, 2010.

[35] M. Acciarri, S. Binetti, A. Le Donne et al., "Development of a hybrid sputtering/evaporation process for $\mathrm{Cu}(\mathrm{In}, \mathrm{Ga}) \mathrm{Se}_{2}$ thin film solar cells," Crystal Research and Technology, vol. 46, no. 8, pp. 871-876, 2011.

[36] A. Romeo, M. Terheggen, D. Abou-Ras et al., "Development of thin-film $\mathrm{Cu}(\mathrm{In}, \mathrm{Ga}) \mathrm{Se}_{2}$ and CdTe solar cells," Progress in Photovoltaics, vol. 12, no. 2-3, pp. 93-111, 2004.

[37] F. Pianezzi, A. Chirilä, P. Blösch et al., "Electronic properties of $\mathrm{Cu}(\mathrm{In}, \mathrm{Ga}) \mathrm{Se}_{2}$ solar cells on stainless steel foils without diffusion barrier," Progress in Photovoltaics, vol. 20, no. 3, pp. 253-259, 2012.

[38] D. Rudmann, D. Brémaud, A. F. Da Cunha et al., "Sodium incorporation strategies for CIGS growth at different temperatures," Thin Solid Films, vol. 480-481, pp. 55-60, 2005.

[39] D. Rudmann, A. F. da Cunha, M. Kaelin et al., "Efficiency enhancement of $\mathrm{Cu}(\mathrm{In}, \mathrm{Ga}) \mathrm{Se}_{2}$ solar cells due to post-deposition $\mathrm{Na}$ incorporation," Applied Physics Letters, vol. 84, no. 7, pp. 1129-1131, 2004.

[40] J. E. Granata and J. R. Sites, "Impact of sodium in the bulk and in grain boundaries of $\mathrm{CuInSe}_{2}$," in Proceedings of the 2nd World Conference on Photovoltaic Solar Energy Conversion, p. 604, Vienna, Austria, 1998.

[41] I. D. Olekseyuk, I. V. Dudchak, and L. V. Piskach, "Phase equilibria in the $\mathrm{Cu}_{2} \mathrm{~S}-\mathrm{ZnS}-\mathrm{SnS}_{2}$ system," Journal of Alloys and Compounds, vol. 368, no. 1-2, pp. 135-143, 2004.

[42] H. Katagiri, K. Jimbo, W. S. Maw et al., "Development of CZTSbased thin film solar cells," Thin Solid Films, vol. 517, no. 7, pp. 2455-2460, 2009.

[43] B. Shin, O. Gunawan, Y. Zhu, N. A. Bojarczuk, S. J. Chey, and S. Guha, "Thin film solar cell with $8.4 \%$ power conversion efficiency using an earth-abundant $\mathrm{Cu}_{2} \mathrm{ZnSnS}_{4}$ absorber," Progress in Photovoltaics, vol. 21, no. 1, pp. 72-76, 2013.

[44] N. Kamoun, H. Bouzouita, and B. Rezig, "Fabrication and characterization of $\mathrm{Cu}_{2} \mathrm{ZnSnS}_{4}$ thin films deposited by spray pyrolysis technique," Thin Solid Films, vol. 515, no. 15, pp. 5949-5952, 2007.

[45] K. Tanaka, N. Moritake, and H. Uchiki, "Preparation of $\mathrm{Cu}_{2} \mathrm{ZnSnS}_{4}$ thin films by sulfurizing sol-gel deposited precursors," Solar Energy Materials and Solar Cells, vol. 91, no. 13, pp. 1199-1201, 2007. 
[46] A. Ennaoui, M. Lux-Steiner, A. Weber et al., " $\mathrm{Cu}_{2} \mathrm{ZnSnS}_{4}$ thin film solar cells from electroplated precursors: novel low-cost perspective," Thin Solid Films, vol. 517, no. 7, pp. 2511-2514, 2009.

[47] S. C. Riha, B. A. Parkinson, and A. L. Prieto, "Solution-based synthesis and characterization of $\mathrm{Cu}_{2} \mathrm{ZnSnS}_{4}$ nanocrystals," Journal of the American Chemical Society, vol. 131, no. 34, pp. 12054-12055, 2009.

[48] T. K. Todorov, K. B. Reuter, and D. B. Mitzi, "High-efficiency solar cell with earth-abundant liquid-processed absorber," Advanced Materials, vol. 22, no. 20, pp. E156-E159, 2010.

[49] T. K. Todorov, J. Tang, S. Bag et al., "Beyond 11\% efficiency: characteristics of state-of-the-art $\mathrm{Cu}_{2} \mathrm{ZnSn}(\mathrm{S}, \mathrm{Se})_{4}$ solar cells," Advanced Energy Materials, vol. 3, no. 1, pp. 34-38, 2012.

[50] EPIA-European Photovoltaic Industry Association, Solar Generation 6, EPIA, 2011.

[51] W. Shockley and H. J. Queisser, "Detailed balance limit of efficiency of p-n junction solar cells," Journal of Applied Physics, vol. 32, no. 3, pp. 510-519, 1961.

[52] G. Conibeer, "Third-generation photovoltaics," Materials Today, vol. 10, no. 11, pp. 42-50, 2007.

[53] A. W. Bett, F. Dimroth, and G. Siefer, "Multijunction concentrator solar cells," Springer Series in Optical Sciences, vol. 130, pp. 67-87, 2007.

[54] M. A. Green, E. C. Cho, Y. Cho et al., "All-silicon tandem cells based on, "artificial" semiconductor synthesised using silicon quantum dots in a dielectric matrix," in Proceedings of the 20th European Photovoltaic Solar Energy Conference, p. 3, Barcelona, Spain, 2005.

[55] M. Morgano, I. Perez-Wurfl, and S. Binetti, "Nanostructured silicon-based films for photovoltaics: recent progresses and perspectives," Science of Advanced Materials, vol. 3, no. 3, pp. 388-400, 2011.

[56] S. Benagli, J. H. itzel, D. Borrello et al., "High performance LPCVD-ZNO TCO used in p-i-n amorphous silicon \& micromorph tandem devices prepared in industrial Kai-M R\&D reactor," in Proceedings of the 23rd European Photovoltaic Solar Energy Conference, Valencia, Spain, 2008.

[57] N. H. Karam, R. King, B. T. Cavicchi et al., "Development and characterization of high-efficiency $\mathrm{Ga}_{0.5} \mathrm{In}_{0.5} \mathrm{P} / \mathrm{GaAs} / \mathrm{Ge}$ dualand triple-junction solar cells," IEEE Transactions on Electron Devices, vol. 46, no. 10, pp. 2116-2125, 1999.

[58] ASTM E-490-00, Standard Extraterrestrial Spectrum Reference, 2000.

[59] ASTM G173-03, Standard Tables for Reference Solar Spectral Irradiances: Direct Normal and Hemispherical on $37^{\circ}$ Tilted Surface, 2012.

[60] M. Yamaguchi, "Radiation-resistant solar cells for space use," Solar Energy Materials and Solar Cells, vol. 68, no. 1, pp. 31-53, 2001.

[61] J. F. Geisz and D. J. Friedman, "III-N-V semiconductors for solar photovoltaic applications," Semiconductor Science and Technology, vol. 17, no. 8, pp. 769-777, 2002.

[62] M. Stan, D. Aiken, B. Cho et al., "High-efficiency quadruple junction solar cells using OMVPE with inverted metamorphic device structures," Journal of Crystal Growth, vol. 312, no. 8, pp. 1370-1374, 2010.

[63] C. V. Falub, H. von Känel, F. Isa et al., "Scaling hetero-epitaxy from layers to three-dimensional crystals," Science, vol. 335, no. 6074, pp. 1330-1334, 2012.

[64] A. Le Donne, M. Acciarri, D. Narducci, S. Marchionna, and S. Binetti, "Encapsulating $\mathrm{Eu}^{3+}$ complex doped layers to improve
Si-based solar cell efficiency," Progress in Photovoltaics, vol. 17, no. 8, pp. 519-525, 2009.

[65] S. M. Sze and K. K. Ng, Physics of Semiconductor Devices, John Wiley \& Sons, New York, NY, USA, 2007.

[66] O. E. Semonin, J. M. Luther, S. Choi et al., "Peak external photocurrent quantum efficiency exceeding $100 \%$ via MEG in a quantum dot solar cell," Science, vol. 334, no. 6062, pp. 1530-1533, 2011.

[67] R. Heitz, H. Born, F. Guffarth et al., "Existence of a phonon bottleneck for excitons in quantum dots," Physical Review B, vol. 64, no. 24, Article ID 241305, 4 pages, 2001.

[68] G. J. Conibeer, C.-W. Jiang, D. König, S. Shrestha, T. Walsh, and M. A. Green, "Selective energy contacts for hot carrier solar cells," Thin Solid Films, vol. 516, no. 20, pp. 6968-6973, 2008.

[69] A. Luque and A. Martí, "Increasing the efficiency of ideal solar cells by photon induced transitions at intermediate levels," Physical Review Letters, vol. 78, no. 26, pp. 5014-5017, 1997.

[70] A. Martí, E. Antolín, C. R. Stanley et al., "Production of photocurrent due to intermediate-to-conduction-band transitions: a demonstration of a key operating principle of the intermediateband solar cell," Physical Review Letters, vol. 97, no. 24, Article ID 247701, 2006.

[71] A. Scaccabarozzi, S. Adorno, S. Bietti, M. Acciarri, and S. Sanguinetti, "Evidence of two-photon absorption in strain-free quantum dot GaAs/AlGaAs solar cells," Physica Status Solidi, vol. 7, no. 3, pp. 173-176, 2013.

[72] H. A. Atwater and A. Polman, "Plasmonics for improved photovoltaic devices," Nature Materials, vol. 9, no. 3, pp. 205-213, 2010.

[73] A. de Vos, "Detailed balance limit of the efficiency of tandem solar cells," Journal of Physics D, vol. 13, no. 5, pp. 839-846, 1980. 


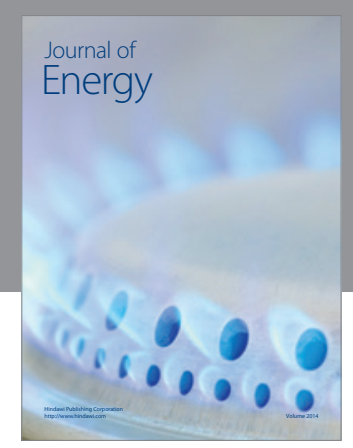

Journal of

Industrial Engineering
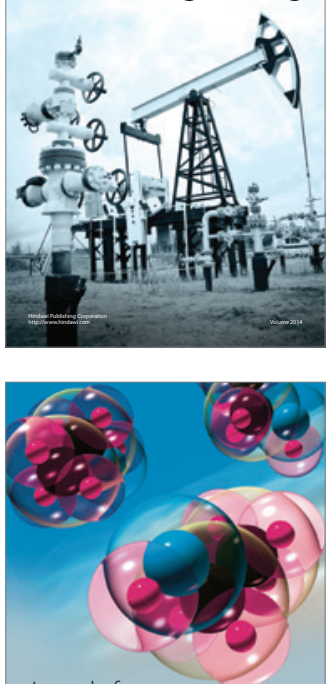

Fuels
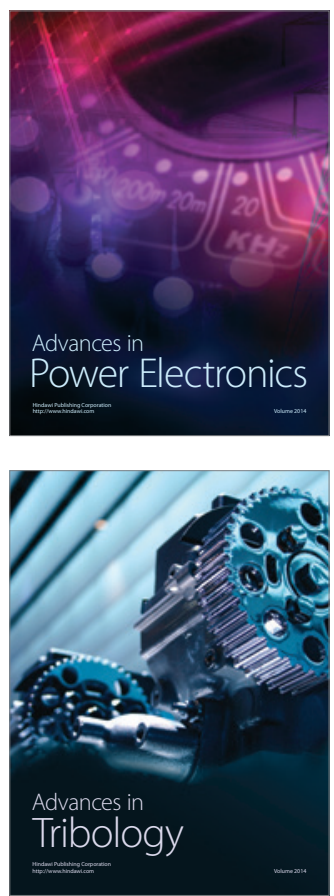

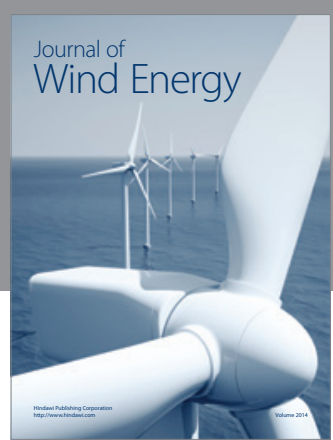

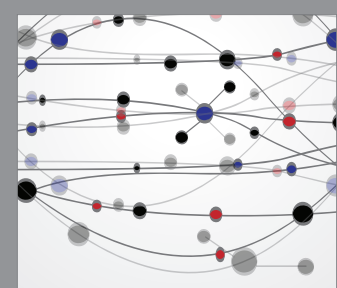

The Scientific World Journal

Submit your manuscripts at http://www.hindawi.com

Journal of

Structures
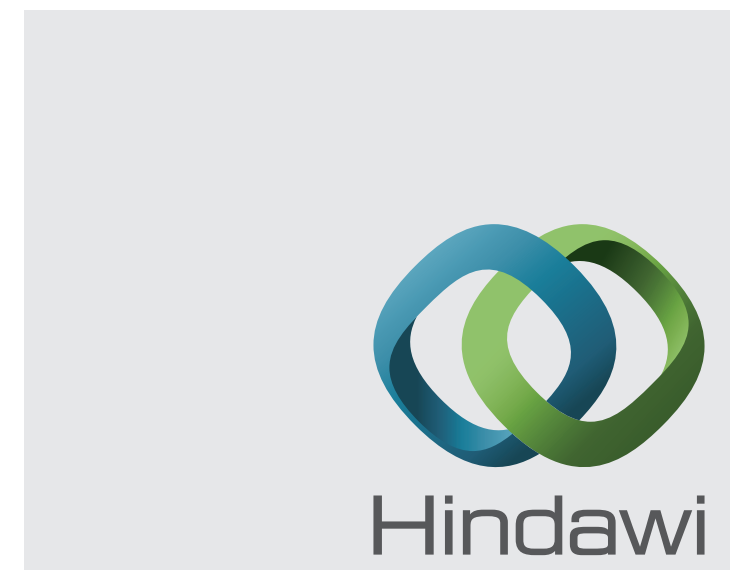

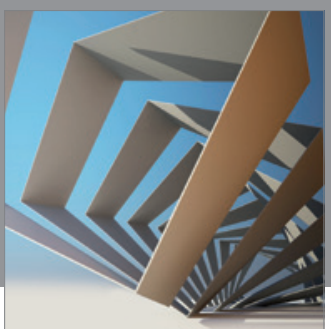

Rotating

Machinery
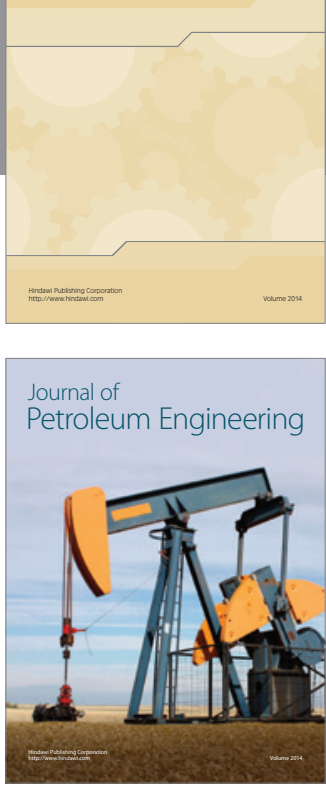

Journal of

Solar Energy
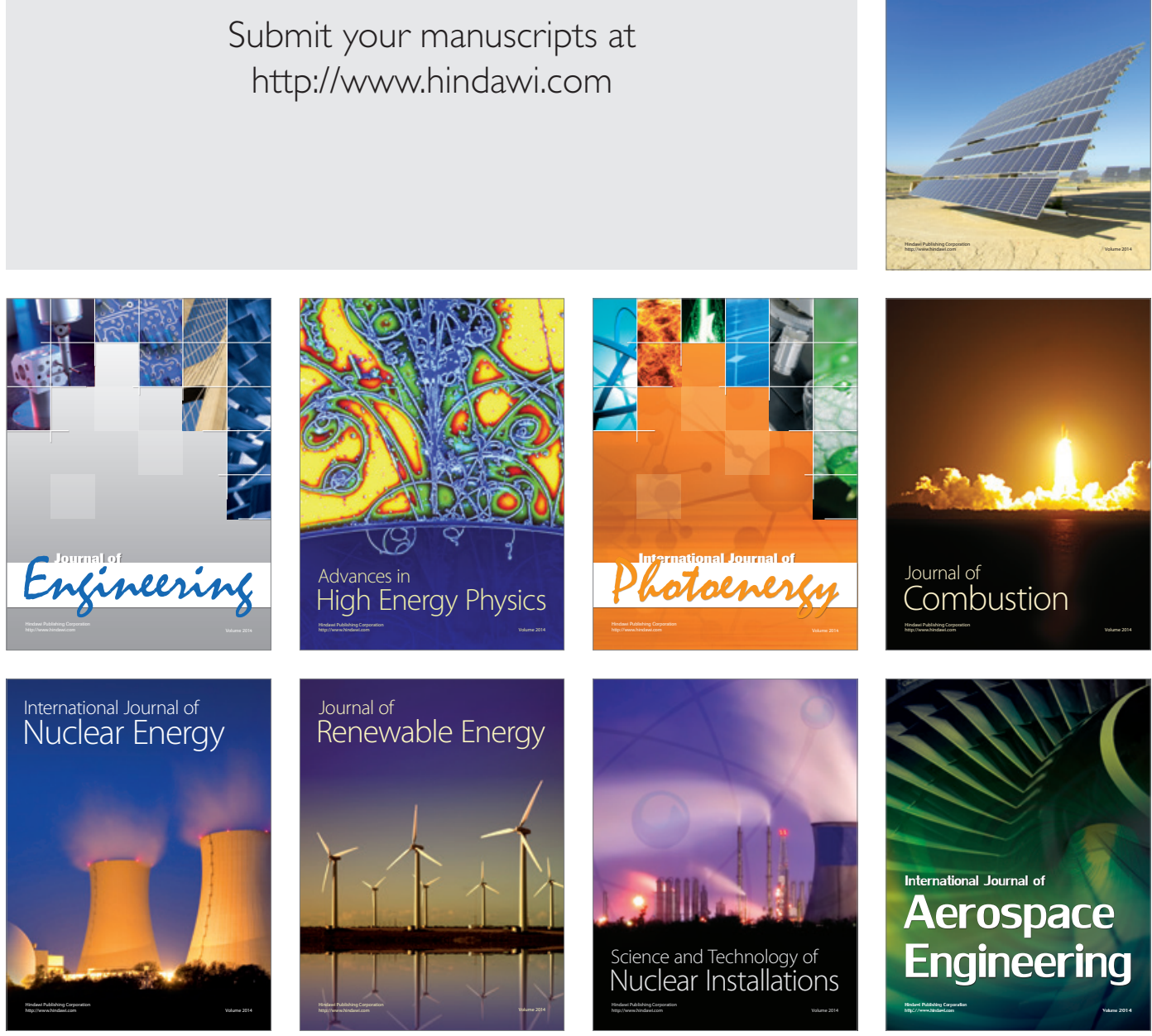